\title{
THE EXPLANATION OF SELF-STERILITY
}

\author{
E. M. EAST, Bussey Institution, Forest Hills, Mass.
}

$\mathrm{I}^{\mathrm{N}}$ N A recent paper by C. W. Moore' on the subject of self-sterility, several ill-advised statements were made to which attention should be called.

The paper begins with the sentence:

Several who have made a study of the problem of the inheritance of self-sterility of plants have obtained results which did not point to any one definite manner in which flowers act when self-pollinated.

One might read in to the meaning of this statement either that there was great difference of opinion regarding the behavior of self-sterile plants or that little was known regarding self-sterility before the appearance of the paper under discussion. As a matter of fact a great many details regarding self-sterile plants -are known. Darwin dealt with the matter at some length, and more recently extended researches by Jost, Correns, Compton and Stout have appeared. The present writer has also investigated the subject rather minutely although only preliminary reports of the work have been published. As to the gross facts, there is not a great difference of opinion among the later writers. Each has found that pollen grains germinate after self-pollination as readily as they do after cross-pollination, but that they grow more slowly, and the present writer has determined that the growth curves of self-pollen tubes are approximately straight lines, while growth curves of cross-pollen tubes are similar to those of autocatalytic reactions. Each has found that there is cross-sterility of the same nature as self-sterility. In other words, the plants of a self-sterile race are not only self-incompatible, but some combinations are cross-incompatible. The differences of opinion come in interpretation of these results, and these differences are due largely, we believe, to the fragmentary character of the evidence.
Moore founds an hypothesis by which to explain self-sterility on the supposed fact that self-tubes are greater in diameter than cross-tubes. In fact this seems to be the main thesis of his paper. He says:

. . the greater width of the self-pollinated pollen tubes of Tradescantia is due to the fact that the food supply is more favorable to the nourishment of a self-pollen tube than it is to a cross-pollen tube. On account of the abundant food supply the pollen tubes did not lengthen, but grew wider since they were in a very favorable medium. By this hypothesis it is possible to explain most of the data here presented.

What Moore did was to measure short self-pollen tubes and long cross-pollen tubes as he distinctly states on page 204 . Now if he had measured self-pollen tubes and cross-pollen tubes of the same length, as he should have done, it is almost certain that he would have found them to be of the same width. At least this is the observation of the writer on numerous pistils of three different self-sterile species of Nicotiana. Moore's main thesis, therefore, seems to be based upon an improper observation.

The second point made in the paper, involving a criticism of the present writer, is similarly without foundation He says:

He [East] states that "all gametes having in their hereditary constitution something different from that of the cells of the mother plant, however, can provoke the proper secretion to stimulate the pollen tube growth, reach the ovary before the flower wilts, and produce seeds." From this it may be inferred that there may be an enzyme in the pollen grain that in a cross-pollination is able to induce the stigma to excrete a stimulating substance so that the pollen tube is able to grow. In a self-pollination this enzyme is not able to act. However, if this were the case, when a few cross-pollen grains were placed on a selfpollinated stigma, they would be expected to germinate and cause the stigma to produce the stimulating substance. Thus the pollen tubes from the self-pollination would also benefit by the stimulating influence and should b

' JoURNAL' OF HEREDITY, viii, 203-207, 1917. 
able to grow and bring about fertilization. However, the work on alsike clover does not support this hypothesis.

This idea of Moore is diametrically opposed to modern conceptions of colloid chemistry. Plant enzymes do not pass freely through cell membranes and diffuse through the tissues. They are very local in their action as is shown very clearly by the definite lines of demarcation between colors in certain corollas. Nevertheless, to be on the safe side the writer made two experiments calculated to test the effect of cross-pollen tubes on self-pollen tubes. In the first experiment five pistils were pollinated with a definite number of cross-pollen grains under a binocular and then covered with self-pollen. Three capsules matured, and yielded seeds as follows:

$\begin{array}{ccc}\text { Nistil No. } & \text { No. cross-pollen } \\ \text { groins used } & \text { No. seeds produced } \\ 1 & 51 & 46 \\ 2 & 48 & 42 \\ 3 & 50 & 41\end{array}$

Since the experimental error was probably only plus or minus three pollen grains, the indications are clearly that no self-pollen tubes contributed toward the production of these seeds. But, of course, the matter is not proved definitely. A mote critical test was the following: Three pistils of a whiteflowered plant breeding true for white flowers were selfed. After a few hours compatible pollen from a plant breeding true for red flowers was placed upon these same stigmas. Capsules full of seed were obtained. These seed, if produced only by the action of the pollen from the red flowered plant should produce only red flowered plants since red is dominant. Not all the plants from these seeds have blossomed, but thus far no white-flowered plants have been produced.

The main theses defended in Moore's paper, therefore, are both based upon incorrect observations and upon fallacious reasoning.

\section{The Mentality of Orphans}

The mentality of orphans and of children who are dependent on public care for other reasons, is low, according to Professor Rudolf Pintner of Ohio State University, in the Journal of Edrcational Psychology (April, 1917). Stenquist, Thorndike and Trabue, testing dependent children in New York, found that in general they fell below public school children of the same age, in intelligence. Hall secured similar results in New York state orphan asylums. Streeter, testing the children in the orphanages of New Hampshire, found $49 \%$ normal, $30 \%$ backward and $21 \%$ feebleminded. Pintner tested 82 children for the Ohio State Board of Charities and found that only $37 \%$ were normal, $19 \%$ being feebleminded and the rest backward. A test which he made of 106 children in a county children's home showed $7 \%$ who were bright, $35 \%$ normal, $11 \%$ feebleminded, and the remainder backward.

\section{Disabled Soldiers Marry in England}

As soldiers who were disabled at the front are likely to be of superior eugenic quality, it is important to their nation that their disabilities should not prevent them from leaving descendants. The English Eugenics Review, which has interested itself in this problem, publishes some interesting facts in its last issue. Of 440 blinded soldiers entering St. Dunstan's Hostel, 144 were previously married and 296, or rather more than two-thirds, were single. Of these single men 55 , or $18 \%$, have married since their disablement. It is noted that the wives are to be considered in every case as extremely suitable, and almost without exception as unusually good looking. It is evident, therefore, that the idea suggested recently in England of finding wives for blinded soldiers among those girls who are physically so unattractive as otherwise to be destined to celibacy, is not being carried out. 